\title{
Avaliação Ambiental Estratégica para Gestão Municipal do Turismo: um estudo no município de Bueno Brandão, MG $^{1}$
}

\section{Strategic Environmental Assessment for Municipal Tourism Planning: a case study in Bueno Brandão - MG}

\author{
Clara Carvalho de Lemos ${ }^{2}$ \\ Marcelo Pereira de Souza ${ }^{3}$
}

\begin{abstract}
Resumo
No Brasil, a gestão dos impactos ambientais ocasionados pela atividade turística, geralmente, acontece em momentos tardios, ou seja, o estímulo ao turismo, via de regra, precede o planejamento. Nessa discussão ganha destaque a necessidade de utilização de um instrumento que forneça oportunidade para avaliação de impacto ambiental em situações mais estratégicas como políticas, planos e programas. O presente estudo apresenta a avaliação ambiental estratégica (AAE) como um instrumento a ser utilizado na gestão estratégica dos impactos ambientais da atividade turística e evidencia as perspectivas de sua aplicação para o planejamento turístico, trazendo um estudo de caso realizado no Município de Bueno Brandão, MG. A partir das informações obtidas em campo, o trabalho oferece subsídios e recomendações para uma possível aplicação da avaliação ambiental estratégica na realidade brasileira.
\end{abstract}

Palavras-chave: gestão do turismo; impactos ambientais; avaliação ambiental estratégica.

\begin{abstract}
In Brazil, the management of environmental impacts caused by the tourism industry usually occurs too late in the planning process. Therefore the encouragement of tourism activities usually precedes the planning process. This discussion highlights the call for using a tool that provides opportunity for environmental impact assessment in more strategic situations like policies, plans and programs. This study presents Strategic Environmental Assessment (SEA) as a tool used for strategic assessment of tourism environmental impacts and highlights possibilities for its application in tourism planning, presenting a case study conducted in the town of Brandão Bueno, MG. Considering locally gathered information, this study offers contributions and recommendations for possible implementation of strategic environmental assessment within Brazilian local context.
\end{abstract}

Keywords: tourism management; environmental impacts; strategic environmental assessment.

\footnotetext{
${ }^{1}$ Este trabalho foi realizado com o apoio do Conselho Nacional de Desenvolvimento Científico e Tecnológico $\mathrm{CNPq}$ - Brasil e do Programa Petrobrás Ambiental.

${ }^{2}$ Doutoranda do Programa de Pós-Graduação em Ciências da Engenharia Ambiental da Escola de Engenharia de São Carlos. Mestre em Ciências da Engenharia Ambiental pela Universidade de São Paulo, Escola de Engenharia de São Carlos. Bacharel em Turismo pela Universidade de Fortaleza. Email: clara@sc.usp.br.

${ }^{3}$ Engenheiro Civil. Professor Titular do Departamento de Biologia da Faculdade de Filosofia, Ciências e Letras de Ribeirão Preto, Universidade de São Paulo. Pesquisador do CNPq.mps@sc.usp.br.
} 


\section{Introdução}

Atualmente o Brasil e diversos outros países têm experimentado o desafio de buscar formas de inserir um instrumento de política ambiental que garanta a consideração e avaliação de questões ambientais no processo de tomada de decisão em situações estratégicas. Esse instrumento tem sido chamado de avaliação ambiental estratégica (AAE), que tem o intuito de fornecer aos propositores e também responsáveis pelas decisões uma compreensão abrangente das implicações ambientais e sociais de suas ações. As estratégias de desenvolvimento, portanto, são construídas tendo como base e referência um conjunto mais abrangente de perspectivas, objetivos e restrições. Essas questões incluem considerações que, sem a AAE, só surgiriam no momento do estudo de impacto ambiental para projetos (quando requisitado). A adoção da avaliação ambiental estratégica poderia, portanto, representar um avanço no momento em que trata de questões que vão além e ultrapassam as ações pontuais tratadas nos estudos de impacto ambiental de projetos.

A AAE, portanto, representa uma forma que se convencionou adotar para identificar o processo formal de avaliação, o mais cedo possível, dos impactos ambientais de decisões tomadas em políticas, planos e programas (PARTIDÁRIO, 1996). Além de possivelmente compensar algumas limitações dos estudos de impacto ambiental de projetos, a avaliação ambiental estratégica é vista como um instrumento com grande potencial de promoção do desenvolvimento sustentável. Isso porque, segundo Therivel e Partidário (1996), essa ferramenta deve proporcionar a consideração de todas as implicações ambientais de planos governamentais e realçar o papel dessas políticas como indutoras de formas mais sustentáveis de desenvolvimento.

O propósito da AAE, portanto, é o de incorporar às tomadas de decisão a consideração, o mais cedo possível, das suas conseqüências ao meio ambiente, assim como as necessidades e opiniões da sociedade. Esse conceito considera como parte do processo a consulta pública e a análise de alternativas, antes que haja comprometimento irreversível de recursos para políticas, planos e programas (CLARK, 2000).

A generalização e a globalização da problemática ambiental impuseram sobre diversas disciplinas o imperativo de internalizar em seus paradigmas metodológicos e teóricos os efeitos e problemas práticos do desenvolvimento econômico (LEFF, 2002). Com o turismo 
não é diferente e diversos estudos mostram as conseqüências negativas que formas predatórias de turismo podem causar no meio natural bem como a necessidade de se buscar instrumentos que garantam o desenvolvimento responsável e sustentável da atividade.

Por isso, este trabalho evidencia as perspectivas de aplicação da avaliação ambiental estratégica para o planejamento turístico, trazendo um estudo de caso realizado no Município de Bueno Brandão, localizado no Estado de Minas Gerais, com o intuito de, a partir das informações obtidas em campo, oferecer subsídios e recomendações para uma possível aplicação da avaliação ambiental estratégica em um plano de desenvolvimento turístico.

\section{A Necessidade da Gestão Estratégica no Turismo}

São vários os fatores que influenciam a ocorrência de impactos ambientais negativos de atividades turísticas e a intensidade e freqüência com que eles ocorrem. Esses impactos devem variar, principalmente, de acordo com (COHEN, 1978; SIMPSON e WALL, 1999; ORGANIZAÇÃO MUNDIAL DO TURISMO, 2003):

\subsection{A intensidade do uso turístico}

O volume de visitantes, o tempo de permanência no local e a concentração da utilização turística em locais e épocas específicas determinam a intensidade do uso turístico. Quanto maior é o fluxo, maior deverá ser a pressão que esses visitantes acarretam sobre as áreas naturais e urbanas e os recursos a elas associados.

\subsection{Tipo de utilização ou de atividade turística}

O tipo de atividade turística (atividades desenvolvidas e as facilidades requeridas) está diretamente relacionado aos impactos ocasionados. Algumas atividades são mais intensivas no uso de recursos naturais, emitem mais ruídos e resíduos e/ou demandam maior quantidade de facilidades (infra-estrutura, suprimentos, mão-de-obra, matérias-primas etc.).

\subsection{Características da área de destino}

Os ambientes diferem em termos de fragilidade, sensibilidade e capacidade de recuperação. As características do meio ambiente, portanto, influenciam na sua capacidade de absorver impacto. Algumas áreas são mais suscetíveis ao dano ambiental do que outras e suas 
características naturais é que devem condicionar sua capacidade de receber fluxos turísticos e a infra-estrutura associada.

\subsection{Gestão e contexto político}

Os impactos estão intimamente relacionados aos tipos de planejamento e estratégias de gerenciamento associados à atividade turística. A maioria dos casos de impactos negativos da atividade ocorre em áreas onde há pouco controle, gerenciamento de má qualidade ou inexistente e um sistema legal falho.

Em um estudo realizado no Parque Nacional do Itatiaia, Serrano (1997) analisou o uso do local por turistas e visitantes e chama a atenção para o fato de que o argumento do impacto turístico, que por vezes justifica a interdição de algum tipo de uso do local por visitantes, em geral, mascara a insuficiência ou a incompetência administrativa, pois os impactos inerentes da atividade turística em áreas naturais podem ser atenuados por uma série de medidas de controle e gestão.

Esse fato confirma a idéia de que são as estratégias de gerenciamento e os instrumentos de gestão utilizados que devem influenciar de modo mais significativo os níveis de impacto ocasionados pela atividade turística, já que a maioria dos casos de impactos negativos do turismo ocorre em áreas onde há pouco controle, gerenciamento de má qualidade ou inexistente e um sistema legal falho; e são as estratégias de gestão que permitem o controle dos outros fatores causadores de impacto.

Para isso, nas últimas décadas, vários instrumentos de gestão foram desenvolvidos, com especial referência ao uso turístico de áreas naturais, no sentido de resolver os conflitos e impactos do turismo (BOYD e BUTLER, 1996).

A capacidade de carga é um desses instrumentos, já amplamente aplicado em estratégias de controle de fluxos turísticos em áreas naturais, especialmente a partir da década de 1990 . No entanto, Lemos e Montaño (2006) já chamaram atenção para o fato de que estabelecer número de visitantes para áreas naturais é muito mais um conceito intuitivo do que científico e que a magnitude do impacto não é necessariamente condicionada pelo número de turistas. Wearing e Neil (2001) também são críticos desse método e garantem que a prática de limitar o número de visitantes é, muitas vezes, uma solução imprópria e simplista. 
Outros sistemas de gerenciamento e manejo de visitantes baseados em condições sociais e ambientais desejáveis representam uma reformulação do conceito de capacidade de carga, de forma a compensar e/ou suprir algumas de suas limitações, apresentando uma abordagem baseada no desenho de indicadores, cenários e monitoramento. Exemplos desses sistemas de manejo são o LAC (Limits of Acceptable Change), VIM (Visitor Impact Managment), VERP (Visitor Experience Resource Protection), dentre outros.

Freixêdas-Vieira, Passold e Magro (2000) mostram que esses métodos apresentam em comum o fato de se basearem em condições sociais e ambientais desejadas para o futuro, e, por meio do monitoramento da área, avalia-se se as ações de manejo estão produzindo os resultados esperados sem alterar outras características da experiência ou do ambiente.

Nota-se, portanto, uma evolução do manejo da visitação pública em áreas naturais, partindo do simples controle do número de pessoas, estabelecido pela capacidade de carga, a instrumentos que estabelecem padrões e condições ambientais de mudanças aceitáveis e o contínuo monitoramento dessas questões. Constata-se, porém, que, apesar de algumas diferenças de enfoque e metodologia, esses instrumentos têm em comum o fato serem pouco aplicáveis a outras situações que não a visitação em áreas naturais protegidas (LEMOS e MONTAÑO, 2006).

Pires (2005) já chamou atenção para o fato, ao afirmar que, quando se trata de considerar espaços de recreação e turismo não protegidos na forma de unidades de conservação, como as praias, cidades, áreas rurais ou outros espaços com recursos naturais demandados para a mesma finalidade, esses modelos têm a sua aplicação, se não inviabilizada, altamente dificultada.

A avaliação de impacto ambiental, outro instrumento amplamente utilizado em várias partes do mundo, também apresenta importante interface com o turismo, pois cada vez mais se reconhece a sua importância como parte de avaliações de propostas de desenvolvimento turístico (HUNTER, 1995).

Butler (1991 apud HUNTER, 1995), contudo, já observava que, em muitas localidades, e por muitos anos, as avaliações de impacto de empreendimentos turísticos ocorriam, na maioria das vezes, de forma reativa, quando já haviam sido aprovados esses projetos. 
Essa constatação não é exclusiva do setor de turismo e a realidade mostra que a avaliação de impacto ambiental nem sempre é capaz de garantir que as questões ambientais sejam incorporadas na concepção e elaboração de projetos e empreendimentos. Morgan e Onorio (2000) ainda chamam a atenção para o fato de que os impactos cumulativos do turismo devem ser considerados, o que, geralmente, não acontece mediante a avaliação de impacto ambiental de projetos, que considera apenas os impactos diretos de certos empreendimentos.

O estudo de impacto ambiental de projetos, portanto, é insuficiente para avaliar questões estratégicas como os impactos indiretos e globais de um empreendimento; ou, como instrumento para garantir o desenvolvimento mais sustentável de um setor, como é o caso do turismo. Assim, torna-se evidente a necessidade de uma avaliação das políticas governamentais de incentivo ao turismo, antes da aprovação de projetos específicos para determinadas localidades.

Além disso, constata-se atualmente, que, no Brasil, grandes investimentos em complexos turísticos construídos pela iniciativa privada, a maioria dos quais estimulados e incentivados por governos estaduais, não obedecem a preceitos do planejamento sustentável do turismo (BENI, 2001); ou seja, o próprio Poder público também não consegue garantir que suas ações de estímulo a essa atividade ocorram sem prejuízos ao meio ambiente e aos reais interesses das populações locais.

Nesses casos, a ponderação dos fatores ambientais e sociais não é compromisso explícito de políticas de incentivo a grandes investimentos, em que os fatores econômicos são mais considerados. Já se chamou a atenção para o fato de que a necessidade de abordagens estratégicas na gestão dos impactos negativos da atividade é um dos preceitos e lacunas de maior urgência na atualidade (LEMOS, 2007).

Isso porque, ao analisar os instrumentos de gestão ambiental mais comumente usados no turismo, fica evidente o fato de que o gerenciamento de impactos acontece em momentos tardios, ou seja, o estímulo ao turismo precede o planejamento, e as estratégias de gestão, geralmente, estão relacionadas ao esforço em minimizar os impactos que o aumento do fluxo turístico causa em áreas naturais, desconsiderando outras conseqüências inevitáveis que essa atividade pode trazer para uma região, como a pressão sobre o arranjo territorial, a pressão 
sobre os recursos naturais e as reservas de água, o aumento da produção de resíduos e efluentes etc.

\section{Avaliação Ambiental Estratégica: uma alternativa para a gestão estratégica do turismo}

O propósito da avaliação ambiental estratégica é avaliar, o mais cedo possível, o impacto de questões estratégicas, mas também auxiliar a integração das questões ambientais, sociais e econômicas durante a formulação de políticas (DALAL-CLAYTON e SADLER, 2005). Também se considera como parte do processo a consulta pública e a análise de alternativas, antes que haja comprometimento irreversível de recursos para políticas, planos e programas em questão.

No turismo, a necessidade da AAE ganha força, pois, em muitos destinos turísticos, a explosão de investimentos em obras e empreendimentos de grande porte - como hotéis, resorts, estradas e aeroportos - são resultados de políticas de atração e incentivo por parte do Poder público, em nome da criação de empregos e da entrada de divisas. Além disso, muitas das conseqüências negativas do turismo são resultados de impactos induzidos e sinérgicos. A necessidade de avaliações estratégicas, portanto, é indiscutível.

A política de turismo é definida por Beni (2001) como um conjunto de decisões que, integradas harmonicamente no contexto da política nacional de desenvolvimento, orientam a condução do setor e regulam as ações a serem executadas, as quais se traduzem em planos e programas de desenvolvimento setorial. Programas e planos de desenvolvimento, por sua vez, influenciam os projetos, por isso, acredita-se que a AAE pode condicionar o desenvolvimento de certos projetos, assim como reduzir esforços e recursos dos estudos de impacto ambiental.

Além disso, à medida que o mundo volta suas atenções para a busca do desenvolvimento sustentável, o conceito de AAE aufere cada vez mais importância e urgência (CLARK, 2000). O turismo, como atividade consumidora de recursos naturais, não foge a essa regra. $\mathrm{O}$ desafio da conservação ambiental como fator condicionante para a sustentabilidade do turismo é discutido e estudado pela comunidade científica mundial. 
A experiência prática e a produção científica a respeito da AAE crescem, o que contribui para o aperfeiçoamento técnico e a consolidação conceitual desse instrumento. Lemos (2007) destacou que, no Brasil, nota-se um crescente interesse tanto no âmbito governamental quanto acadêmico, no que se refere à aplicação da AAE em território nacional. É preciso, porém, cautela ao analisar e caracterizar algumas experiências como AAE propriamente ditas. DalalClayton e Sadler (2005) utilizam o termo para-SEA para designar estudos que não se adequam ao conceito formal de $\mathrm{AAE}$ ou às especificações contidas em lei, mas que têm algumas de suas características.

Pode-se afirmar que, embora princípios e diretrizes pareçam ter alcançado certo consenso entre pesquisadores e profissionais, na prática a $\mathrm{AAE}$ ainda apresenta diversas formas e abordagens. No presente trabalho, defende-se a necessidade de reflexão a respeito de um modelo de avaliação ambiental estratégica que seja adaptado à realidade brasileira, mas que não deixe de considerar alguns princípios básicos que devem acompanhar a aplicação desse instrumento em qualquer situação. A AAE, portanto, deve garantir que as questões ambientais sejam levadas em consideração na concepção de ações estratégicas, e não se resuma a aprovação ou rejeição de propostas de políticas.

\section{Desafios para Adoção da AAE no Âmbito Municipal: o caso do município de Bueno Brandão, MG}

A região montante da bacia hidrográfica do Mogi-Guaçu apresenta vários problemas ambientais e alterações na qualidade da água, ocasionados pelas atividades antrópicas, especialmente produções agrícolas e pastoris (BRIGANTE e ESPÍNDOLA, 2003). Por essa razão, as questões de conflito, que originaram os principais impactos ambientais observados nessa região, passaram a ser objeto de estudo e intervenção do Núcleo de Estudos de Ecossistemas Aquáticos, do Departamento de Hidráulica e Saneamento, da Escola de Engenharia de São Carlos, com patrocínio do Programa Petrobrás Ambiental, com o intuito de promover ações capazes de auxiliar a redução dos impactos antrópicos, redirecionando o uso e manejo dos recursos hídricos existentes e interferindo nos aspectos sociais (educação ambiental) e econômicos (agricultura, piscicultura e turismo) da região. 
Os municípios da região estratégica de montante da bacia do Mogi-Guaçu têm como base econômica as atividades rurais (agrícolas e pecuárias) e de produção de malhas (confecções, vestuário). A situação de dependência em relação a esses setores econômicos tem se mostrado insuficiente e limitada para a manutenção da qualidade de vida das comunidades locais. A equipe do Projeto Mogi-Guaçu, portanto, estabeleceu como uma de suas linhas de ação, o estímulo à criação de estratégias que propiciem oportunidades alternativas de desenvolvimento, conciliáveis com a conservação dos recursos naturais (HANAI, ESPÍNDOLA e BRIGANTE, 2007).

Dentre essas estratégias, o turismo emergiu como atividade potencialmente atrativa no que se refere ao desenvolvimento de alternativas econômicas aliadas ao comprometido com a conservação dos recursos naturais. Nesse contexto, o Município de Bueno Brandão se destaca por já apresentar certo grau de desenvolvimento relacionado a atividades turísticas, ainda carecendo, porém, de ações de planejamento e investimento para o setor.

É necessário destacar que da mesma forma que não era intenção do Projeto Mogi-Guaçu intervir diretamente na elaboração do plano de desenvolvimento turístico da cidade, também não foi intento deste trabalho realizar uma avaliação ambiental estratégica, mas avaliar as condições locais para uma possível inserção da AAE e de que maneira isso poderia ser realizado frente à realidade local.

O estudo de caso no Município de Bueno Brandão permitiu confrontar os princípios indispensáveis para a realização da $\mathrm{AAE}$ com a realidade de um município brasileiro de potencial turístico. Para isso foi necessária a realização de pesquisa direta, com observações diretas em campo e pesquisa documental. Isso porque, segundo Beni (2001), por mais lógica, coerente e precisa que seja toda e qualquer apresentação teórica, esta nunca deve prescindir do embasamento da pesquisa feita junto aos órgãos, entidades e pessoas que acionam a matéria objeto do estudo, pois é esta investigação prática e concreta que poderá oferecer possíveis correções no encaminhamento de factíveis intervenções na realidade. A observação direta em campo, portanto, foi complementada com entrevistas semi-estruturadas com representantes do Departamento de Turismo, Lazer, Cultura e Desporto, do Departamento de Desenvolvimento Rural e Meio Ambiente e representantes da sociedade civil no Conselho Municipal de Turismo e no Conselho Municipal de Desenvolvimento Ambiental. As considerações finais e 
as sugestões feitas aqui, portanto, são baseadas numa análise empírica das evidências e informações coletadas a partir de observações locais e entrevistas.

Por isso, a pesquisa versou sobre os principais aspectos que envolvem a gestão do turismo no Município, ou seja, a maneira pela qual o Poder público local se organiza e se aparelha para administrar o setor de Turismo, os instrumentos de gestão utilizados, as esferas de participação da sociedade, as informações ambientais disponíveis e outros fatores e princípios indispensáveis para se realizar uma avaliação ambiental estratégica.

\section{Bueno Brandão: caracterização geral}

Localizado no sul do Estado de Minas Gerais, distante $458 \mathrm{~km}$ da capital Belo Horizonte e próximo à fronteira com o Estado de São Paulo, o Município de Bueno Brandão faz parte de uma região estratégica e privilegiada pela beleza de seus vales, paisagem montanhosa exuberante, clima ameno e diversas nascentes que, por conta do relevo, formam uma grande quantidade de quedas d'água.

Com $355 \mathrm{Km}^{2}$ de extensão e $70 \%$ de seu território montanhoso, Bueno Brandão está localizada a $1.200 \mathrm{~m}$ de altitude, o que condiciona seu clima a temperaturas amenas, com médias anuais de $24,3^{\circ} \mathrm{C}$ (INSTITUTO DE DESENVOLVIMENTO INTEGRADO DE MINAS GERAIS, 2006).

Em Bueno Brandão, é o setor de serviços, aqui incluso o comércio e o turismo, que mais contribui com o Produto Interno Bruto (PIB) municipal. Mesmo com um percentual bem menor de mão de obra empregada, quase $19 \%$ da população ocupada, o setor atingiu, no ano de 2005, mais que o dobro das receitas provenientes do setor agropecuário. O turismo, atividade que tem como uma de suas bases a prestação de serviços e influencia diversos setores da economia, parece contribuir para esses resultados no Município de Bueno Brandão (INSTITUTO DE DESENVOLVIMENTO INTEGRADO DE MINAS GERAIS, 2006; INSTITUTO BRASILEIRO DE GEOGRAFIA E ESTATÍSTICA, 2006).

As características geográficas, paisagísticas e climáticas, somadas à receptividade da população local, fazem de Bueno Brandão um local cada vez mais procurado por turistas. $\mathrm{O}$ crescimento dessa atividade, portanto, está sendo impulsionado, principalmente, pelo forte 
apelo das características naturais da região e se intensificou como atividade econômica de relevância nos últimos cinco anos.

Dentre os atrativos naturais que despertam o interesse dos visitantes destacam-se os picos, com altitudes que chegam a cerca de $1.500 \mathrm{~m}$, e, principalmente, as cachoeiras, o que fez com que a cidade passasse a ser denominada "cidade das cachoeiras". Elas podem variar desde grandes quedas d'água de até $100 \mathrm{~m}$ de altitude a pequenas corredeiras com grutas e lagos, usadas para banho, contemplação e prática de esportes. Nem todas, porém, estão abertas para visitação turística, seja pela dificuldade de acesso, falta de infra-estrutura, ou até mesmo limitação por parte dos proprietários das terras.

Apesar da contribuição da atividade para o desempenho de setor de serviços, a infra-estrutura turística ainda é, em grande parte, informal. Identificando a oportunidade de diversificar as opções de receitas, muitos proprietários rurais adaptam suas propriedades para receber visitantes, por meio do aluguel de quartos, chalés ou espaços para acampamento. Essas propriedades, apesar de informais, já oferecem uma grande quantidade de serviços relacionados à vida no campo.

Já existem também agências de turismo receptivo, com guias treinados, que oferecem atividades como passeios em trilhas, caminhadas de contemplação e esportes em áreas naturais. Além disso, alguns moradores locais alugam suas casas para temporadas, feriados ou finais de semana. Por outro lado, Hanai, Espíndola e Brigante (2007) destacaram que o grande fluxo de visitantes, principalmente nos feriados e finais de semana, lota os estabelecimentos de hospedagem (pousadas e hotéis e campings) e tem ocasionado diversos impactos negativos nos locais naturais de visitação, principalmente em cachoeiras e rios, comprometendo a conservação das áreas naturais e a qualidade da experiência de visitação.

Assim, a emergência do turismo, apesar de já apresentar resultados positivos em relação às oportunidades econômicas que estão surgindo no município de Bueno Brandão, impõe também uma série de questionamentos sobre a forma como ocorre o desenvolvimento da atividade, sua relação com os recursos naturais e culturais da região, os impactos positivos e negativos decorrentes e os possíveis conflitos com outras atividades econômicas, especialmente a agropecuária. $\mathrm{O}$ fato de o turismo apresentar um crescimento significativo 
nos últimos anos, portanto, faz com que essas questões sejam alvo de discussões por parte do poder público, empresários e alguns representantes da sociedade civil local.

\section{Subsídios para Avaliação Ambiental Estratégica}

\subsection{Estrutura administrativa e institucional de gestão do turismo em Bueno Brandão}

Atualmente, a gestão do turismo na estrutura administrativa pública é feita pelo Departamento de Turismo, Cultura, Desporto e Lazer, que era conduzido, no momento da realização da pesquisa, por três funcionários e três monitores.

Como órgão responsável pela formulação e implementação das políticas públicas relacionadas ao turismo, esse órgão deve se posicionar se não de forma direta na avaliação ambiental estratégica, pelo menos de maneira muito próxima. É necessário ressaltar que, mesmo em casos em que a administração pública contrate consultores ou organizações externos, o departamento responsável pela direção do setor não pode abrir mão de ser um dos principais atores nesse processo.

A utilização de uma consultoria externa é positiva em experiências iniciais devido à limitada capacidade técnica e profissional de planejadores e funcionários públicos locais que desconhecem o instrumento, especialmente na realidade brasileira. Além disso, uma equipe de profissionais externos pode facilitar a mediação entre grupos de interesses diversos e trazer mais imparcialidade para a avaliação.

Por outro lado, é o quadro técnico e funcional da prefeitura que conhece a realidade do turismo na cidade, assim como as limitações financeiras e institucionais que o poder público enfrenta. A proximidade entre consultores externos e os membros do governo tomadores de decisão é essencial para que as recomendações propostas na AAE estejam próximas da realidade e da capacidade institucional e política dos órgãos governamentais responsáveis pela implementação das ações. Do contrário, corre-se o risco de a AAE se transformar, como já destacado, num estudo de gaveta.

A participação de planejadores e tomadores de decisão também pode ser crucial para garantir que as sugestões apontadas pelos relatórios da AAE serão realmente incorporadas às ações e políticas públicas e, assim, postas em prática. Como já identificado na experiência 
internacional (LEMOS, 2007), se os responsáveis pela tomada de decisão e a instituição propositora da política não participarem de forma ativa na avaliação fica mais difícil garantir que os resultados e as recomendações da AAE sejam realmente levados em consideração.

Além disso, a necessidade de se fazer desse instrumento um elemento intrínseco da elaboração da política faz com que cada ambiente político e organizacional tenha que, necessariamente, desenvolver os mecanismos administrativos e institucionais necessários à realização da AAE (PARTIDÁRIO, 1996), e, sem a participação desses tomadores de decisão, a AAE corre o risco de se tornar um documento sem desdobramentos práticos.

\section{2. Âmbito de aplicação}

Já é possível encontrar experiências de elaboração de políticas municipais de turismo, especialmente, em importantes centros receptores como Brotas, SP e Bonito, MS. Nesses casos, freqüentemente, as políticas são estabelecidas na forma de lei municipal, de modo a estabelecer instrumentos regulatórios e de gestão para o desenvolvimento turístico local.

A adoção da AAE para ações estratégicas municipais em planos de turismo pode ser mais viável por duas razões. A experiência de aplicação da AAE em políticas ainda é pouco comum, especialmente pelo fato de se tratar de questões mais conceituais, com direcionamentos muito abrangentes. Ainda existem, portanto, muitos desafios nesse campo. A análise da experiência mundial (LEMOS, 2007) mostrou, inclusive, que, mesmo nos casos em que a AAE é aplicada em políticas, essas se aproximam muito do conceito de planos, com objetivos específicos e voltados para a ação. Além disso, o principal instrumento para planejamento setorial do turismo no âmbito municipal ainda é o plano de desenvolvimento turístico.

É importante destacar que esses planos não podem estar dissociados de outras estratégias regionais, estaduais e nacionais. A discussão sobre a aplicação da AAE no âmbito municipal não pode desconsiderar a adoção desse instrumento em outros níveis governamentais, pois são essas questões que garantem avaliações em cascata, com cada nível de planejamento influenciando e estabelecendo melhores contextos para os níveis seguintes. 
Isso porque a AAE, adotada em todos esses níveis (PPPs), pode poupar tempo e recursos já que as questões avaliadas nas políticas não precisam ser reavaliadas e rediscutidas nos níveis subseqüentes. Além disso, uma política sujeita à AAE deve influenciar de forma proativa a ação seguinte e estabelecer as bases para a elaboração de planos e programas, e, conseqüentemente, projetos também mais sensíveis às questões ambientais (DALALCLAYTON e SADLER, 2005).

Apesar de ser importante para o direcionamento da atividade turística em Bueno Brandão, não existe atualmente uma política ou um plano formal que indique as diretrizes de orientação do turismo local. Essa situação está relacionada ao fato de o turismo ser um fenômeno recente no Município e, dessa forma, apenas recentemente passou a ser alvo de maior atenção do poder público local. Além disso, o órgão responsável pela gestão do setor ainda acumula muitas funções, com limitada capacidade financeira, pessoal e técnica. A atuação municipal em relação à gestão do turismo tem sido muito mais reativa, em função do surgimento de demandas. Por essas razões, acredita-se que a elaboração, implementação e monitoramento de um plano de turismo deve se configurar como um grande desafio para o poder público local.

Por outro lado, a municipalidade dispõe de outros instrumentos e políticas correlatas, alguns já adotados em Bueno Brandão, e que podem incorporar questões relativas ao desenvolvimento turístico local, como o Plano Diretor, as Leis de Uso e Ocupação do Solo, iniciativas de planejamento de infra-estrutura viária, gestão de resíduos, saneamento etc.

\subsection{Integração}

A quase ausência de ações de planejamento integradas, que caracterizam a intersetorialidade, não é atributo exclusivo do Município de Bueno Brandão. Essa é uma falha no sistema político-institucional brasileiro e deve configurar como um grande desafio na inserção de questões ambientais na gestão local do turismo.

Em Bueno Brandão, essas ações conjuntas entre órgãos da administração pública em Bueno Brandão são fundamentalmente reativas e se resumem à solução de problemas de ordem prática, no que diz respeito às demandas administrativas diárias de cada departamento, o que dá espaço para o surgimento de processos lentos e burocráticos. 
Se mesmo o planejamento tradicional, pelo menos no âmbito da atividade turística, sofre de carências administrativas, técnicas e pessoais, as ações integradas dos demais órgãos da administração local deve ser um passo ainda mais distante dessa realidade setorializada e burocrática. Esse fato também dificulta a integração metodológica. Já que não existe um padrão ou uma cultura de planejamento, a administração pública deverá encontrar meios próprios de inserção da $\mathrm{AAE}$, de acordo com suas possibilidades e capacidades.

O planejamento do turismo já exige a consideração de políticas, planos e programas relacionados, por se tratar de uma atividade tão multi-setorial. A AAE deve estimular a consolidação desse processo, fazendo das questões ambientais um ponto de convergência entre os diversos atores da administração pública.

Além disso, deve-se buscar contextualizar as ações locais com a realidade nacional, estadual e regional, identificando direções, objetivos e metas de outros PPPs; as suas implicações para o Plano de Desenvolvimento Turístico de Bueno Brandão e as respostas do plano a esses requisitos, exigências e objetivos. Por outro lado, sem a adoção da AAE em todos os níveis governamentais corre-se o risco de se reafirmar objetivos equivocados, que não foram sujeitos à $\mathrm{AAE}$.

\subsection{Participação e transparência}

Um dos principais motivos que justificam a necessidade de adoção da $\mathrm{AAE}$ diz respeito às possibilidades que ela traz ao estabelecer mecanismos de participação pública em discussões relevantes em níveis estratégicos (DALAL-CLAYTON e SADLER, 2005). Therivel (2004) acentua que no mínimo a AAE fornece oportunidade para que o público comente sobre a proposta, antes que ela seja aprovada. No melhor dos casos, a AAE permite que o público possa realmente influenciar de forma ativa a tomada de decisão.

A equipe do Projeto Mogi-Guaçu levantou e analisou algumas informações referentes à opinião da população local sobre mobilização e expectativas geradas pelo desenvolvimento turístico. Esses resultados mostram um quadro com importantes informações a respeito da disposição dessas pessoas em participar das decisões locais no que diz respeito ao desenvolvimento turístico. 
Apesar de o turismo ser uma das principais atividades econômicas e empregar considerável quantidade de mão-de-obra, a população de Bueno Brandão considera saber pouco $(82 \%$ dos entrevistados) ou nada (18\% dos entrevistados) sobre turismo (HANAI, ESPÍNDOLA e BRIGANTE, 2007).

Observou-se também que $43 \%$ dos moradores entrevistados não possuem interesse em se envolver nas decisões sobre o futuro do desenvolvimento turístico. Esse dado pode apontar, conforme afirmaram Hanai, Espíndola e Brigante (2007), para o pouco interesse da população local em participar de decisões sobre o turismo, o que reflete a necessidade de ações que promovam mobilização da sociedade e que introduzam princípios de cooperativismo. Mas também pode ser resultado de uma parcela da população que não se sente parte do turismo, ou seja, pessoas que não estão envolvidas profissionalmente com essa atividade ou não se sentem afetadas por ela no seu dia-a-dia.

É correto afirmar que o turismo local ainda vem ocorrendo de forma mais espontânea do que planejada, com pouca profissionalização e desconhecimento da população em geral, porém, o fato de que $57 \%$ da população têm interesse em participar das decisões sobre o desenvolvimento turístico local é considerável e significativa. O que é necessário destacar nesses casos é a questão da representatividade dessa população nos canais de participação e sua capacidade de influenciar e intervir de forma direta na tomada de decisão.

Já existem, em Bueno Brandão, alguns canais, instituídos por lei, que fornecem oportunidades de participação de representantes da sociedade em discussões de questões de interesse público e que podem representar oportunidades para futuras experiências de avaliação ambiental estratégica em turismo. Nesse caso destaca-se aqui o Conselho Municipal de Turismo (COMTUR) e o Conselho Municipal de Desenvolvimento Ambiental (COMDEMA).

O COMTUR foi instituído em Bueno Brandão em 1997, por meio da Lei Municipal $\mathrm{N}^{\circ} 022 / 97$, que caracteriza o Conselho como órgão de caráter consultivo e deliberativo, para assessoramento da municipalidade em questões referentes ao desenvolvimento turístico do município. Dentre as principais competências do COMTUR está a de debater sobre os temas de interesse turístico para a cidade, manter atualizado o cadastro de informações turísticas, formular as diretrizes básicas para a política municipal de turismo, desenvolver programas e projetos de interesse turístico, promover e divulgar atividades ligadas ao turismo, propor e 
divulgar critérios para a programação e para as execuções financeiras e orçamentárias do Fundo Municipal de Turismo, dentre outras.

Apesar de existir em forma de lei, o COMTUR nunca esteve realmente ativo no cumprimento de suas funções e vários são os problemas creditados a essa inoperância. O principal deles diz respeito à composição dos representantes. De acordo com a lei, esse órgão deve ser constituído por dezoito membros efetivos, com 6 representantes do poder público local (Câmara Municipal e Prefeitura), 6 representantes da iniciativa privada (empresários dos mais diversos ramos do turismo como agências, hotéis, empresas de transporte, entretenimento e restaurantes), 3 representantes de associações e sindicatos, 2 representantes da imprensa e um representante do COMDEMA. Há várias divergências quanto ao número de componentes e argumenta-se que alguns membros são dispensáveis por não representarem grupos de interesse.

Além disso, não existe uma posição política local, por parte do executivo, no sentido de valorizar e fortalecer os mecanismos de representação e participação da sociedade em tomadas de decisão. Essa falta de compromisso acaba por esvaziar esses instrumentos que só existem na forma de lei. Muitas vezes impera o argumento de que as informações estratégicas são "segredo de Estado", o que dificulta a democratização do processo de discussão pública de interesses coletivos. Essa constatação vai de encontro às necessidades atuais da sociedade, que demanda um novo modelo de gestão turística, com ampla participação da iniciativa privada e de diversos segmentos da sociedade civil organizada. Com essa proposta, o Estado evidencia a intenção de restringir a sua atuação no turismo e de dividir a responsabilidade das funções assumidas no transcurso da história (QUEIROZ, 2001).

Outro órgão colegiado, também criado por lei em 1997 (Lei Municipal №1.280, de 03.06.1997), e que passa por uma situação semelhante, é o Conselho Municipal de Desenvolvimento Ambiental - COMDEMA, órgão de caráter consultivo de assessoramento ao poder executivo municipal e deliberativo em relação a algumas questões como emissão de alvarás de localização e funcionamento de atividades potencialmente poluidoras, bem como sobre solicitações de certidões para licenciamento. O conselho é composto, de forma paritária, por representantes do poder público e da sociedade civil. 
O COMDEMA de Bueno Brandão é um exemplo emblemático de falta de representatividade da sociedade no que deveria ser um órgão consultivo e participativo. A sua atuação se resume a um presidente, indicado pelo executivo, que atua de forma centralizada e alheia aos dispositivos previstos por lei de representação e participação de outros grupos e representantes da sociedade. Essa falta de representatividade está relacionada com o risco que os canais institucionais de participação correm de funcionarem como instrumentos legitimadores de certa classe política local ou de grupos influentes e dominantes economicamente, deixando à revelia os anseios e as demandas de uma parcela menos favorecida da sociedade local. Por isso, acredita-se que o fim da cultura de centralização que existe em Bueno Brandão e em muitos municípios brasileiros só deve ocorrer com o fortalecimento de organizações sociais e com o compromisso político em fortalecer os mecanismos de participação.

\subsection{Referências, informações e monitoramento}

Um dos princípios da AAE é que políticas, planos e programas sejam avaliados de acordo com objetivos, parâmetros ou políticas de sustentabilidade, ou seja, que exista uma base de referências que possam balizar a construção dessas políticas e sejam incorporadas às questões estratégicas. Essas referências estão diretamente relacionadas a um outro princípio que é a coleta, produção e sistematização contínua de informações ambientais.

O levantamento, a sistematização e a divulgação de informações ambientais são fatores cruciais na AAE para a tomada de decisão. A decisão será, essencialmente, política, porém, as informações disponibilizadas e as conseqüências avaliadas e tornadas públicas, somadas ao peso da opinião pública, tendem a aumentar a influência das questões ambientais no jogo político.

Uma futura experiência de AAE deve demandar um esforço coletivo de pesquisa e sistematização de informações. Isso porque em Bueno Brandão, assim como em muitos municípios do Brasil, não existe uma base de dados ambientais, ou seja, não há uma cultura de armazenamento e utilização de informações ambientais com o intuito de dar suporte ao planejamento e à tomada de decisão. 
Além disso, a análise da experiência internacional (LEMOS, 2007) mostrou que os estudos trazem um apanhado extenso de informações, muitas vezes desnecessárias e descontextualizadas das questões que realmente interessam na avaliação em foco.

O turismo em Bueno Brandão está baseado quase que integralmente no contato e uso direto e indireto da água e na vivência e apreciação das paisagens e do modo de vida da zona rural. Deve-se buscar, portanto, manter o foco nas questões que realmente interessam nesse segmento, seja para fins de elaboração e avaliação de cenários como para monitoramento, tais como:

- recursos hídricos (aspectos quantitativos e qualitativos);

- uso e ocupação do solo (remanescentes de vegetação nativa, áreas de preservação permanente, zonas de interesse patrimonial e histórico etc.);

- resíduos sólidos (projeções de produção e capacidade de coleta e destinação final etc.);

- danos à biodiversidade (perspectivas de danos à flora e à fauna com as visitas às áreas naturais);

- saúde, bem-estar e inclusão social (identificar possíveis impactos negativos à população local assim como os benefícios auferidos com a atividade).

A utilização dessas informações para avaliação e monitoramento deve depender da capacidade política e institucional de sistematizá-las e torná-las úteis à rotina de planejamento e controle da atividade. Sabe-se das dificuldades e limitações técnicas, financeiras e pessoais para esse esforço. Por outro lado, atualmente, a administração pública dispõe de uma série de possibilidades de parcerias e trabalhos conjuntos com universidades, organizações da sociedade civil, institutos de pesquisa e até com a própria iniciativa privada.

Além disso, é preciso destacar que, freqüentemente, em experiências internacionais, o poder público tem buscado discutir esses parâmetros e indicadores referenciais com representantes da sociedade, de forma que esses já citados podem ser um ponto de partida para discussões e adaptações à realidade local.

Deve demandar tempo e esforço político para que a municipalidade em Bueno Brandão articule uma base de dados que permita a realização de uma avaliação ambiental estratégica, porém, a experiência mostra que nem sempre um apanhado muito extenso de informações é 
necessário ou útil. Além disso, pode-se pensar em pequenos passos iniciais, trabalhando com informações mais básicas e mais acessíveis. O importante é que essa base de informações não seja um retrato instantâneo da realidade, mas seja constantemente atualizada para garantir o monitoramento e a avaliação contínua do desenvolvimento turístico local.

\section{Considerações Finais}

As ações estratégicas relacionadas ao desenvolvimento do turismo no Brasil deveriam levar em consideração as limitações e fragilidades ambientais de cada região. As leis e instrumentos ambientais existentes no país estabelecem uma série de limitações, parâmetros e estratégias de conservação, porém, as políticas de incentivo ao turismo falham ao não incorporar essas questões. Isso porque a gestão do turismo no Brasil carece de um instrumento estratégico que incorpore essas questões ambientais no processo de tomada de decisão.

A avaliação ambiental estratégica surgiu como um instrumento que facilita esse processo, oferecendo oportunidades para a construção de políticas mais sustentáveis e sensíveis à questão ambiental, para uma maior integração e coordenação institucional entre diversos atores e para aumentar e/ou fortalecer os canais de participação pública.

Com base nas questões aqui apresentadas, nas informações e nos resultados obtidos e analisados por meio do estudo de caso, propõe-se um conjunto de ações e situações a serem buscadas no Município de Bueno Brandão, com o intuito de facilitar a consideração das questões ambientais no planejamento e tomada de decisão de políticas de turismo de forma participativa, democrática e transparente, consolidando caminhos para futuras experiências de avaliação ambiental estratégica. Essas questões dizem respeito aos procedimentos necessários para realização da AAE, identificados na revisão da literatura.

A AAE poderia ser adotada numa escala local com intuito de se estimular as discussões acerca dos impactos ambientais decorrentes do turismo e de garantir a inserção dessas questões na tomada de decisão. A AAE deve ser encarada como um instrumento de auxílio à tomada de decisão, e não um procedimento burocrático de aprovação ou rejeição de propostas já elaboradas. 
Deve haver comprometimento, por parte da administração pública, com o desenvolvimento turístico responsável, participativo, socialmente inclusivo e harmonioso com as condições ambientais locais.

Para garantir a inserção dos tomadores de decisão e gestores locais no processo de AAE o Poder público deve buscar o fortalecimento, através de programas de capacitação em planejamento e em avaliação ambiental estratégica, do corpo técnico e das instituições envolvidas na gestão do turismo e do meio ambiente no Município.

Deve-se priorizar abordagens de tomada de decisão participativa por meio do fortalecimento dos mecanismos de participação social (conselhos municipais, organizações da sociedade civil, associações etc.), como espaços para democratização da informação, expressão e debates de interesses coletivos e formulação de políticas sustentáveis.

A AAE não obterá sucesso sem ações e discussões articuladas entre órgãos públicos e setores relacionados, considerando outras políticas, planos e programas, e contribuindo para a busca de objetivos comuns, com maior consideração das questões ambientais de forma interinstitucional.

Deve-se estimular a produção contínua de informações e identificação de requisitos e referências de sustentabilidade por meio do estabelecimento de um sistema transparente de informação, que articule produção, sistematização, democratização e monitoramento de informações ambientais, de forma a orientar o planejamento e a tomada de decisão, bem como possibilitando o envolvimento da sociedade civil.

\section{Referências}

BENI, Mário Carlos. 2001. A Política de turismo. In: TRIGO, Luiz Gonzaga Godoi. (Org.). Turismo. Como aprender, como ensinar. 2.ed. São Paulo: SENAC. v.1, p.177-202.

BOYD, Stephen W.; BUTLER, Richard W. 1996. Managing ecotourism: an opportunity spectrum approach. Tourism Management, London, v.17, n.8, p.557-566, Dec.

BRIGANTE, Janete; ESPÍNDOLA, Evaldo Luiz Gaeta. 2003. Limnologia fluvial: um estudo no rio Mogi-Guaçu. São Carlos: Rima.

BUTLER, Richard W. 1991. Tourism, environment, and sustainable development. Environmental Conservation, vol. 18, $\mathrm{n}^{\circ}$ 3, p. 201-209.

CLARK, Ray. 2000. Making EIA count in decision-making. In: PARTIDÁRIO, M.R.; CLARK, R. (Ed.). Perspectives on strategic environmental assessment. Boca Raton: Lewis. p.15-27. 
COHEN, Erik. 1978. The impact of tourism on the physical environment. Annals of Tourism Research, New York, v.5, n.2, p.215-237, Apr./June.

DALAL-CLAYTON, Barry; SADLER, Barry. 2005. Strategic environmental assessment: a sourcebook and reference guide to international experience. London: Earthscan.

FREIXÊDAS-VIEIRA, Valéria Maradei; PASSOLD, Anna Julia; MAGRO, Teresa Cristina. 2000. Impactos do uso público: um guia de campo para utilização do método VIM. In: II CONGRESSO BRASILEIRO DE UNIDADES DE CONSERVAÇÃO, 2000, Campo Grande. Anais. Campo Grande: REDE NACIONAL PRÓ-UNIDADES DE CONSERVAÇÃO: Fundação O Boticário de proteção à natureza. p. 296-305.

HANAI, Frederico Yuri; ESPÍNDOLA, Evaldo Luiz Gaeta.; BRIGANTE, Janete. 2007. O turismo sustentável como atividade socioeconômica alternativa de desenvolvimento na região da bacia hidrográfica de montante do rio Mogi-Guaçu. In: ESPÍNDOLA, Evaldo Luiz Gaeta; BRIGANTE, Janete. Projeto Mogi-Guaçu: desenvolvendo ações sócio-ambientais. São Carlos: Rima, (no prelo).

HUNTER, Colin. 1995. Environmental impact assessment and tourism development. In: HUNTER, Colin; GREEN, Howard. Tourism and the environment: a sustainable relationship? London: Routledge. Cap.5, p.121-168.

INSTITUTO BRASILEIRO DE GEOGRAFIA E ESTATÍSTICA. 2006. Disponível em: $<$ http://www.ibge.gov.br/cidadesat $>$. Acesso em: 13 mar. 2007.

INSTITUTO DE DESENVOLVIMENTO INTEGRADO DE MINAS GERAIS. 2006. Disponível $\mathrm{em}:<\mathrm{http}: / /$ www.indi.mg.gov.br/municipios/municipios.asp>. Acesso em: 21 mar. 2006.

LEFF, Enrique. 2002. Epistemologia ambiental. 2.ed. Tradução de Sandra Valenzuela. São Paulo: Cortez.

LEMOS, Clara Carvalho. 2007. Avaliação ambiental estratégica como instrumento de planejamento do turismo. 178 f. Dissertação (Mestrado) - Escola de Engenharia de São Carlos. 2007.

; MONTAÑO, Marcelo. 2006. Fundamentos para a adoção de uma abordagem estratégica no planejamento e gestão da atividade turística. Revista OLAM, Rio Claro, v. 6, p. 184-199.

MORGAN, Richard K.; ONORIO, Komeri R. 2000. SEA of the Neiafu master plan, VaVa'u, Tonga. In: PARTIDÁRIO, Maria Rosario; CLARK, Ray. (Ed.) 2000. Perspectives on strategic environmental assessment. Boca Raton: Lewis.

ORGANIZAÇÃO MUNDIAL DO TURISMO. 2003. Turismo internacional: uma perspectiva global. 2.ed. Tradução de Roberto Cataldo Costa. Porto Alegre: Bookman.

PARTIDÁRIO, Maria Rosário. 1996. Strategic environmental assessment: key issues emerging from recent practice. Environmental Impact Assessment Review, New York, v.16, n.1, p.31-55, Jan.

PIRES, Paulo Santos. 2005. "Capacidade de carga" como paradigma de gestão dos impactos da recreação e do turismo em áreas naturais. Turismo em Análise, São Paulo, v.16, n.1, p.5-28.

QUEIROZ, Lúcia Aquino. 2001. A evolução do sistema institucional público do turismo baiano. Bahia Análise \& Dados, Salvador, v. 11, n. 2, p. 20-28, set.

SERRANO, Celia Maria Toledo. 1997. A vida e os parques: proteção ambiental, turismo e conflitos de legitimidade em unidades de conservação. In: SERRANO, Celia Maria Toledo; BRUHNS, Heloisa Turini (Org.). Viagens à natureza: turismo, cultura e ambiente. 5. ed. Campinas: Papirus.

SIMPSON, Patty; WALL, Geoffrey. 1999. Consequences of resort development: a comparative study. Tourism Management, London, v.20, n.3, p.283-296, June.

THERIVEL, Riki. 2004. Strategic environmental assessment in action. London: Earthscan. 
THERIVEL, Riki; PARTIDÁRIO, Maria Rosário. 1996. The Practice of strategic environmental assessment. London: Earthscan.

WEARING, Stephen; NEIL, John. 2001. Ecoturismo: impactos, potencialidades e possibilidades. Barueri: Manole.

Recebido em: 30/03/2009

Aprovado em: 09/11/2009 